\title{
Study on Stability Analysis of Steel Cylinder Retaining Structure
}

\author{
Bin LI ${ }^{123456 a}$ \\ ${ }^{1}$ TianjinPort Engineering Institute Ltd. of CCCC First Harbor Engineering Company Ltd ., Tianjin, 30222 China \\ ${ }^{2}$ Key laboratory of port geotechnical engineering, ministry of communications, PRC Tianjin, 30222 China \\ ${ }^{3}$ Key laboratory of port geotechnical engineering of Tianjin, Tianjin, 30222 China \\ ${ }^{4}$ CCCC First Harbor Engineering Company Ltd., Tianjin, 300461 China \\ ${ }^{5}$ China Key Laboratory of failure mechanism and safety control techniques of earth-rock dam of the Ministry of \\ Water Resources, Nanjing 210029; \\ ${ }^{6}$ Guangxi Key Laboratory of Geomechanics and Geotechnical Engineering Guilin University of Technology, \\ Guilin 541000, China
}

\begin{abstract}
The steel cylinder structure is generally used as a wharf revetment structure. It is necessary to evaluate the safety and stability of the steel cylinder structure as the retaining structure for offshore foundation excavation. In this paper, a large finite element software PLAXIS is used to simulate the safety factor and the structural displacement of the steel cylinder structure in the wave load and the excavation of the foundation. The calculation results show that the overall stability of the steel cylinder is 1.7 when the most unfavorable condition of excavating from the foundation to the bottom of the steel cylinder. The lateral displacement is $572 \mathrm{~mm}$, which meets the safety requirements of the structure. The steel cylinder structure can play a role as the water retaining structure of the cofferdam and the support structure of foundation when it was put into the non-permeable layer.
\end{abstract}

\section{Introduction}

Large diameter steel cylinder is a new type of port engineering structure. The insert type large diameter cylinder has the characteristics of simple structure, reasonable force, low material consumption, fast construction speed and strong adaptability to foundation, so it has been developed rapidly in China in the past ten years. The abroad research on the mechanical behavior and working mechanism of large diameter cylindrical structures is earlier than China [1]. During the construction of Le Havre port in Le Havre, France in 50s, French engineers have begun to study the model experiment of thin shell structure. The relationship between the density of the inner packing and the bearing load, and the contact friction between the backfill and the wall are analyzed, and the influence factors of the change of the lateral pressure in the thin shell [2-3] are discussed.

China began to carry out the relevant experimental research and engineering design is from [4-5] in 1980s. The project has been completed in Fangchenggang, Guangdong, Fangchenggang, 30 thousand tons grain terminal, Shandong Arashiyama port liquid chemical wharf, as well as the 50 thousand ton container terminal of Nansha Panyu, and the large cylinder test section of the Yangtze Estuary. This new structure has a good development prospect in port engineering.

\section{Engineering Survey}

An underground comprehensive pipe gallery is built in a city. The extension section of the city is built in the sea and which is connected to the high speed around the city. According to the design plan, the excavation method of the cofferdam is adopted. In accordance with the design scheme, the steel cylinder cofferdam is used as the supporting structure and seepage proof structure. The purpose of this paper is to analyze the structural stability of steel cylinder structures under wave loads and soil pressure of excavation.

The engineering area is located in the transition zone between the land and shallow bay of the intertidal zone. It belongs to the coastal shoal geomorphology. The water depth is $0.50 \mathrm{~m}$ to $4.80 \mathrm{~m}$ when the tide rises, and the height of the engineering area is $-3.8 \mathrm{~m}$ to $-4.0 \mathrm{~m}$ when the tide is low. No fracture structure in and near the engineering area. The soil properties from top to bottom are artificial fill, marine sedimentary layer, marine-continental alternating sedimentary layer, Alluvial-diluvia layer, residual layer and bedrock layer.

\section{Design Scheme}

A steel cylinder was laid along the axis of the embankment on average (about $-3.85 \mathrm{~m}$ ), and the diameter 
of the steel cylinder was $30.0 \mathrm{~m}$. The top of the steel cylinder is $3.0 \mathrm{~m}$, the height of the bottom is about $-16.0 \mathrm{~m}$, and the long of the steel cylinder is about $19.0 \mathrm{~m}$.

Through the temporary steel cofferdam, water-proof curtain and large excavation foundation, the dry construction of internal foundation can be realized. The steel cylinders are connected by welded web. The area between the steel cylinder and the cylinder and the web is filled with sand backfill. A large excavation scheme is adopted in the internal foundation pit of the steel cylinder cofferdam. The $8 \mathrm{~m}$ working platform is reserved for the original mud surface down to the height of the steel cylinder bottom, and then the foundation pit is excavated according to the slope ratio $1: 3$.

\section{4 model establishment}

\subsection{Parameter selection}

According to the geological data of typical sections, the small strain soil hardening model is used to select the calculation parameters as shown in Table 1.

Table 1 Summary table for calculating parameter selection

\begin{tabular}{|c|c|c|c|c|c|c|c|}
\hline \multicolumn{8}{|c|}{ Soil hardening model } \\
\hline Soil type & $\begin{array}{l}\text { heavy } \\
\left(\mathrm{kN} / \mathrm{m}^{3}\right)\end{array}$ & $\begin{array}{l}\text { cohesion } \\
\left(\mathrm{kN} / \mathrm{m}^{2}\right)\end{array}$ & $\begin{array}{l}\text { friction } \\
\text { angle } \\
\left({ }^{\circ}\right)\end{array}$ & $\mathrm{E}_{50}{ }^{\mathrm{ref}}\left(\mathrm{kN} / \mathrm{m}^{2}\right)$ & $\mathrm{E}_{\mathrm{oed}}{ }^{\mathrm{ref}}\left(\mathrm{kN} / \mathrm{m}^{2}\right)$ & $\mathrm{E}_{\mathrm{ur}}{ }^{\mathrm{ref}}\left(\mathrm{kN} / \mathrm{m}^{2}\right)$ & $\mathrm{e}_{\text {init }}$ \\
\hline silt & 15.1 & 10 & 20 & 3000 & 2000 & $16 \mathrm{e} 3$ & 0.5 \\
\hline Clay & 18.9 & 26.1 & 11 & 5000 & 5000 & $25 \mathrm{e} 3$ & 0.5 \\
\hline $\begin{array}{l}\text { Gravel } \\
\text { sand }\end{array}$ & 20.5 & 9.9 & 6.5 & $10 \mathrm{e} 3$ & 8642 & $20 \mathrm{e} 3$ & 0.5 \\
\hline Silty clay & 18.3 & 38.3 & 18.8 & 3720 & 3720 & $21 \mathrm{e} 3$ & 0.5 \\
\hline $\begin{array}{l}\text { fully } \\
\text { weathered }\end{array}$ & 21 & 30 & 15 & $39 \mathrm{e} 3$ & $39 \mathrm{e} 3$ & $12 \mathrm{e} 4$ & 0.5 \\
\hline $\begin{array}{l}\text { Inner } \\
\text { cylinder } \\
\text { backfill }\end{array}$ & 20.5 & 9.9 & 6.5 & $1 \mathrm{e} 4$ & 8642 & $2 \mathrm{e} 4$ & 0.5 \\
\hline \multicolumn{8}{|c|}{ Linear elastic model } \\
\hline Soil type & $\begin{array}{l}\text { heavy } \\
\left(\mathrm{kN} / \mathrm{m}^{3}\right)\end{array}$ & $\begin{array}{l}\text { Elastic } \\
\text { modulus } \\
\left(\mathrm{kN} / \mathrm{m}^{2}\right)\end{array}$ & $\begin{array}{l}\text { Poisson } \\
\text { ratio }\end{array}$ & $\mathrm{G}\left(\mathrm{kN} / \mathrm{m}^{2}\right)$ & $\mathrm{E}_{\text {oed }}\left(\mathrm{kN} / \mathrm{m}^{2}\right)$ & $\begin{array}{l}\text { cohesion } \\
\left(\mathrm{kN} / \mathrm{m}^{2}\right)\end{array}$ & $\begin{array}{l}\text { friction } \\
\text { angle } \\
\left({ }^{\circ}\right)\end{array}$ \\
\hline $\begin{array}{l}\text { strong } \\
\text { weathering }\end{array}$ & 22 & $3 e 5$ & 0.25 & $12 \mathrm{e} 4$ & $36 \mathrm{e} 4$ & 1500 & 37 \\
\hline $\begin{array}{l}\text { medium } \\
\text { weathering }\end{array}$ & 26 & $2 \mathrm{e} 7$ & 0.2 & $8.3 \mathrm{e} 6$ & $2.2 \mathrm{e} 7$ & 1500 & 37 \\
\hline
\end{tabular}

The PLAXIS3D finite element analysis software is used in this calculation. It has a more comprehensive and rich specialized rock soil constitutive model and an easy to use operation interface designed for the characteristics of geotechnical engineering analysis. Since its introduction, it has been widely recognized in the international geotechnical field because of its high reliability. It is widely used in various geotechnical projects, such as foundation, slope sliding, retaining wall, tunnel, wharf engineering, etc.

The Moore Coulomb model is used for foundation, backfill sand. It is suitable for elastoplastic, nonlinear material, and the mechanical behaviour of general rock and soil, such as slope stability and underground excavation. The Mohr-Coulomb model is based on the irrelevant flow rule, the fully plastic Mohr-Coulomb yield criterion and the material tension limit of soil.

\subsection{Boundary Condition}

In the process of cofferdam forming, the steel cylinder can be regarded as the retaining wall structure of continuous wall. To simplify the calculation, a cylinder width along with length is used for analysis. The displacement boundary conditions of the model along the wall direction are constrained by the roller, that is, the normal displacement of the two sides of the soil and the structure is constrained, and the other two directions are free of displacement. The whole section of the model is calculated. For drainage conditions, the two sides of the model and the bottom are impermeable, and the top is drainage.

The model size is $\mathrm{X}$ direction $100 \mathrm{~m}$ and $\mathrm{Y}$ direction $30.8 \mathrm{~m}$. This model is based on the water surface, for the diameter of the steel cylinder is $15 \mathrm{~m}$, the height of the cylinder $22 \mathrm{~m}$, the bottom of the steel cylinder is -22 (to the gravel bottom), the vice lattice is built on both sides of the steel cylinder which is not permeable; the $24 \mathrm{kN}$ concentrated load is applied to the $1.6 \mathrm{~m}$ underwater as the wave load; excavation of foundation pit to steel cylinder bottom elevation -22 (to gravel bottom); considering the precipitation of internal foundation pit after the formation of steel cylinder cofferdam, final excavation surface is impermeable surface; the construction process are :stress balance / steel cylinder setting (wave loading) / foundation vertical excavation / stability and safety analysis / steel cylinder safety analysis / safety of steel cylinder total of five construction steps. The calculation model is shown in Figure 2. 


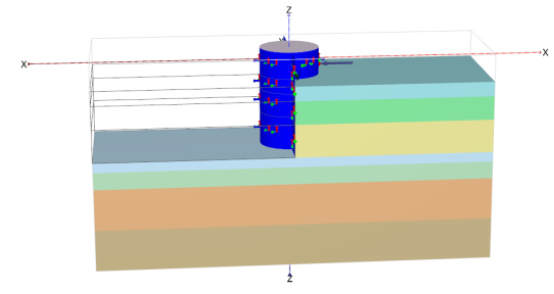

Fig.2 Calculation model for completion of foundation excavation

In numerical calculation, the stress balance is first determined and the initial stress distribution is determined. The initial stress in the soil is affected by the historical influence of the material, which is usually expressed by the vertical effective stress. The horizontal effective stress is related to the vertical effective stress and the side pressure coefficient. In PLAXIS, the initial stress can be generated by the $\mathrm{K}_{0}$ process, and it is usually assumed that the $\mathrm{K}_{0}$ of the normally consolidated soil is related to the friction angle. Through the $\mathrm{K}_{0}$ process, the weight of the soil is all activated and then goes to the construction stage. After the calculation is completed, the deformation of the soil in the foundation and the steel cylinder is output and the safety analysis is carried out.

\section{Results}

After the steel cylinder is finished, the excavation of the foundation in the cofferdam is necessary, so the drainage and part of the excavation should be carried out in the foundation pit. This analysis needs to calculate the stability of the steel cylinder under various working conditions.

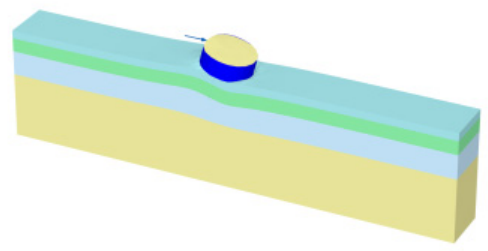

Fig. 3 Displacement diagram of steel cylinder after wave loading

Figure 3 is the displacement diagram of the steel cylinder under the action of the wave load after completion of the steel cylinder. According to the calculation results, the steel cylinder will produce lateral displacement $17 \mathrm{~mm}$ to the inner direction of the foundation pit under the action of the wave load. At this time, the stability safety factor of the steel cylinder is 3.0.

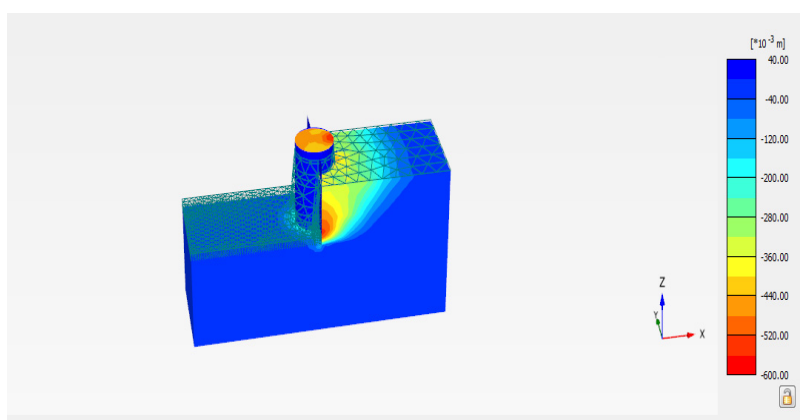

Fig. 4 Images of steel cylinder and ground displacement during excavation of foundation pit

According to the design requirements, Figure 4 is the cloud chart of the steel cylinder and ground displacement when the foundation pit is excavated to the bottom of the steel cylinder. According to the calculation, the maximum lateral displacement of the steel cylinder after the excavation is $572 \mathrm{~mm}$, and the overall stability safety factor of the steel cylinder is 1.7. Figure 5 is a displacement Images of a steel cylinder.
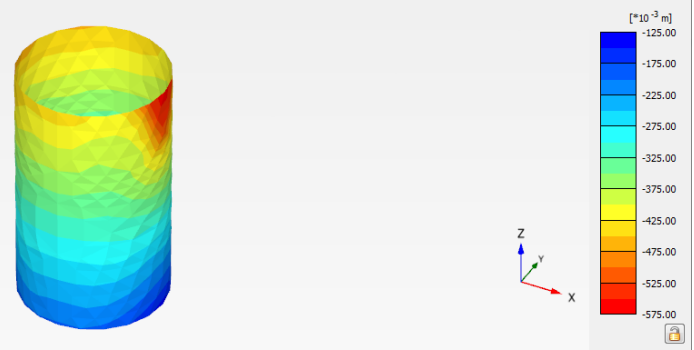

Fig. 5 Displacement cloud chart of steel cylinder structure

As shown in Figure 6, at a certain height, the safety factor increases with the increase in diameter. This is also easy to understand. For the increase of the diameter of the gravity structure, the downward gravity and antioverturning arm can be increased at the same time. However, for Figure 7, the safety factor decreases with the increase of depth when the diameter is fixed, which is obviously contrary to common sense. As for the gravity type anti overturning calculation, the anti-overturning gravity of the packing in the cylinder increases slightly with the height, but the overturning moment of the active earth pressure on the right side of the steel cylinder increases with the height of two times, causing the overturning moment rapid increase and the safety factor to decrease . However, the safety factor increases slowly when the height of steel cylinder is greater than $35 \mathrm{~m}$. Therefore, the anti-overturning checking calculation of gravity structure is only suitable for the case where the insertion depth is small and the filler in the cylinder can participate in the anti-overturning effect to a great extent. 


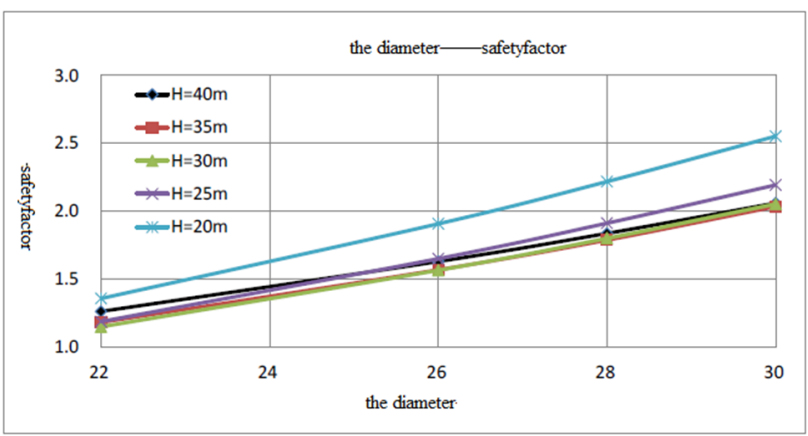

Fig. 6 Relationship between safety factor and diameter

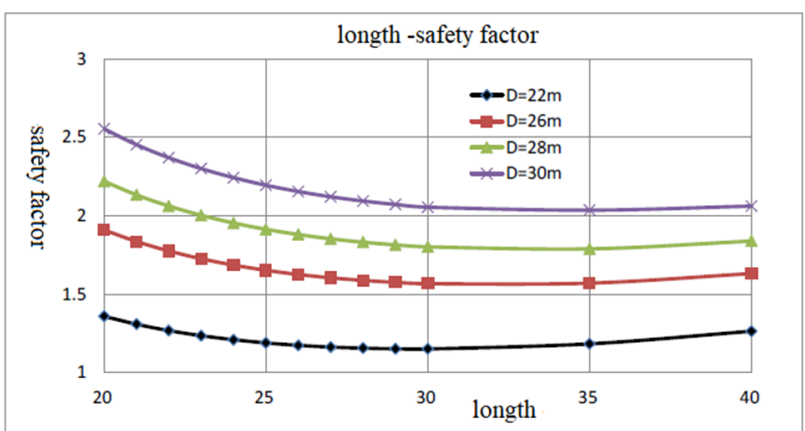

Fig. 7 Relationship between safety factor

\section{Conclusions}

(1) The construction of steel cylinder structure to impervious layer can act as water retaining structure at the sea and retaining structure for foundation pit.

(2) When the foundation pit is excavated to the bottom elevation of the steel cylinder, the overall stability of the steel cylinder is 1.7 , and the lateral displacement is 572 $\mathrm{mm}$, which meets the structural safety requirements.

\section{Acknowledgements}

This research is financially supported by the Open Foundation of Key Laboratory of Failure Mechanism and Safety Control Techniques of Earth-rock Dam of the Ministry of Water Resources (YK916002) ;The project was funded by Guangxi Key Laboratory of Geomechanics and Geotechnical Engineering(16-KF-06); The natural science foundation of Tianjin (No.16JCQNJC06700), (No. 16JCYBJC21700).

\section{References}

1. A. Mecke, I. Lee, J.R. Baker jr., M.M. Banaszak Holl, B.G. Orr, Eur. Phys. J. E 14, 7 (2004)

2. Shao Wei, Liu Xin, Guo Ke, et al. Positioning system for offshore steel cylinder construction: $\mathrm{CN}, \mathrm{CN}$ 103134482 A(2013).

3. Zhang Yang, Xu Xincheng. Application of large diameter steel cylinder in sand replacement and vibration sinking construction. water transport engineering, (1): 220-223. (2018)
4. Zhang Yang, Xu Xin. Application of full-rotation crane ship in vibration sinking construction of large diameter steel cylinder.Marine Engineering, (2): 206210. (2018)

5. Zhang Tiejun, Liu Hao Peng, Yang Runlai. Ship Stationing Technology for Steel Cylinder Vibration Sinking Construction of Hong Kong-Zhuhai-Macao Bridge.China Harbour Construction, (7): 61-63. (2015)

6. Lin Ming, Guan Feng Feng, Kong Linglei, et al. The method of stationing and lifting for steel cylinder vibration sinking construction: CN104097748A. (2014). 